ISSN: 2318 - 1966

v. 3, n. 3

NOVOS RUMOS SOCIOLÓGICOS

jan - jun 2015

Dossiê

\title{
DESEOS PIXELADOS \\ SOCIABILIDAD HOMOERÓTICA MASCULINA EN VILLA MARÍA Y LA REGIÓN (CÓRDOBA, ARGENTINA) A TRAVÉS DE MANHUNT.NET
}

Fernando Peplo

\begin{abstract}
RESUMEN
En este artículo busco analizar los rasgos sobresalientes que adquiere la sociabilidad homoerótica masculina mediada digitalmente, situándome en una región del interior de la provincia de Córdoba (Argentina), y focalizando en el sitio web Manhunt.net. Valiéndome de entrevistas semi-estructuradas, recopilación y análisis de perfiles de usuario y de mi incursión etnográfica en línea durante meses, puedo afirmar que los hombres con deseos/prácticas homoeróticos que residen en el área geográfica investigada usan los medios digitales para buscar compañeros afectivo-sexuales ante la ausencia de locales comerciales tales como cines pornográficos, boliches "alternativos" o saunas. Esta búsqueda se realiza en secreto para evitar ser descubiertos por familiares, colegas del ámbito laboral o educativo ya que en el caso de serlo podrían ser objeto de hostigamiento, estigmatización o discriminación. Tales amenazas nos aportan pistas para comprender por qué los sujetos se empecinan en relacionarse con quienes reúnan la mayor cantidad posible de las características "socialmente deseables".
\end{abstract}

Palabras-clave: sociabilidad, homoerotismo masculino, medios digitales, régimen erótico en línea, pornografía.

\section{PIXELATED DESIRES \\ MALE HOMOEROTIC SOCIABILITY IN VILLA MARÍA AND THE REGION (CÓRDOBA, ARGENTINA) THROUGH MANHUNT.NET}

\begin{abstract}
In this article I seek to analyze the salient features that digitally mediated male homoerotic sociability acquires, locating myself in a non-metropolitan region in the province of Córdoba (Argentina), and focusing in Manhunt.net website. By using semi-structured interviews, collecting and analyzing user profiles and doing an online ethnographic incursion for months, I can posit that men with homoerotic desires/practices in the selected geographical area use digital media to search for affective-sexual mates in the absence of commercial places such as pornographic cinemas, gay discos or bathhouses. This search is done in secret to avoid being discovered by family members, colleagues from work or educational institutions because they could face harassment, stigmatization or discrimination. Such threats provide us some clues to understand why these subjects insist so strongly on wanting those mates to have the largest possible number of the "socially desirable" features.
\end{abstract}

Keywords: sociability, male homoeroticism, digital media, online erotic regime, pornography. 

Deseos pixelados - sociabilidad homoerótica masculina en villa maría y la región (Córdoba,
Argentina) a través de manhunt.net

\section{Palabras preliminares ${ }^{1}$}

Daniel $^{2}$ es un hombre de 55 años, está casado con una mujer, tiene hijos y se desempeña como empleado administrativo en una empresa de la pequeña localidad donde reside desde que nació (situada a unos $120 \mathrm{~km}$ al sur de Villa María). No he tenido el placer de conocer a Daniel personalmente, pero las largas conversaciones que hemos mantenido por chat desde hace varios meses, además de haber contribuido de manera muy productiva con la investigación que vengo desarrollando, me han posibilitado conocerlo como si fuéramos amigos de toda la vida.

Desde un principio, y conforme al protocolo de ética imperante en las investigaciones sociales, revelé a Daniel que me encontraba realizando un trabajo de investigación ("una tesis") con el propósito de comprender, en términos generales, los usos y apropiaciones del sitio web manhunt.net por parte de aquellos hombres con deseos/prácticas homoeróticos ${ }^{3}$, que viven en la localidad de Villa María y alrededores (en un radio de $100 \mathrm{~km}$ a la redonda aproximadamente).

Desde el comienzo de nuestra interacción, percibí que Daniel tenía una necesidad enorme de contar con un confidente, alguien a quien narrarle los secretos que había guardado durante décadas. Considero que su imperiosa necesidad comunicativa para conmigo podría subsumir varios propósitos: 1) compartir con otro aquellas experiencias sexo-afectivas de su juventud que le resultaron muy gratificantes, 2) desahogar emociones reprimidas, 3) no sentirse solo siendo y sintiendo como él ha sido y sentido a lo largo de su vida.

Daniel, al igual que muchos otros hombres con quienes he conversado en línea y fuera de línea, destaca que el acceso a internet le ha permitido explorar deseos homosexuales e interactuar con otros hombres en la misma situación. La principal ventaja, señalan casi unánimemente, es el anonimato que estas nuevas tecnologías posibilitan. Es preciso destacar que, antes que producir un despertar homoerótico en mis interlocutores, la internet sólo habría cumplido el rol de facilitador de sus deseos homoeróticos reprimidos/aplazados.

Cayetano (43 años), de profesión chef, vive con su esposa y los 2 hijos de ambos en una localidad situada a $60 \mathrm{~km}$ de Villa María. En una entrevista que mantuve con él una tarde

\footnotetext{
${ }^{1}$ Este artículo es el resultado parcial de una investigación de Doctorado. Agradezco a Richard Miskolci por las sugerencias realizadas.

2 Para resguardar el anonimato de mis interlocutores, modifiqué sus nombres. Asimismo, cuando sus localidades de residencia tenían menos de 40.000 habitantes, decidí no mencionarlas ni aportar descripciones muy específicas que pudieran contribuir a la identificación de los sujetos de estudio.

3 Prefiero utilizar el término "homoerótico" porque, a diferencia de "homosexual", no tiene connotaciones patológicas o desviantes. Por otra parte, no está asociado a una identidad determinada, fija o sustantiva.
} 
NORUS - v3, n.3 jan - jun 2015.

que se encontraba solo en casa, me contó que descubrió el sitio manhunt.net, tras recibir un correo electrónico donde se lo publicitaba. Según él, la recepción de ese mensaje no habría sido fortuita sino que debió haberse producido como consecuencia de su acceso a una página de pornografía gay (gaymaletube.com), donde se le requirió ingresar su dirección de correo electrónico. Tanto Daniel como Cayetano acceden a internet desde computadoras de escritorio de uso compartido, motivo por el cual han aprendido las técnicas para no dejar rastros de su navegación, ya sea borrando el historial de sitios visitados o utilizando la opción de navegación Exploración de InPrivate ofrecida por el browser de Microsoft, Internet Explorer.

Conocí a Daniel y Cayetano a través del sitio manhunt.net, donde creé un perfil de usuario cuya descripción explicitaba mi condición de estudiante de postgrado y cuál era el objeto de mi búsqueda.

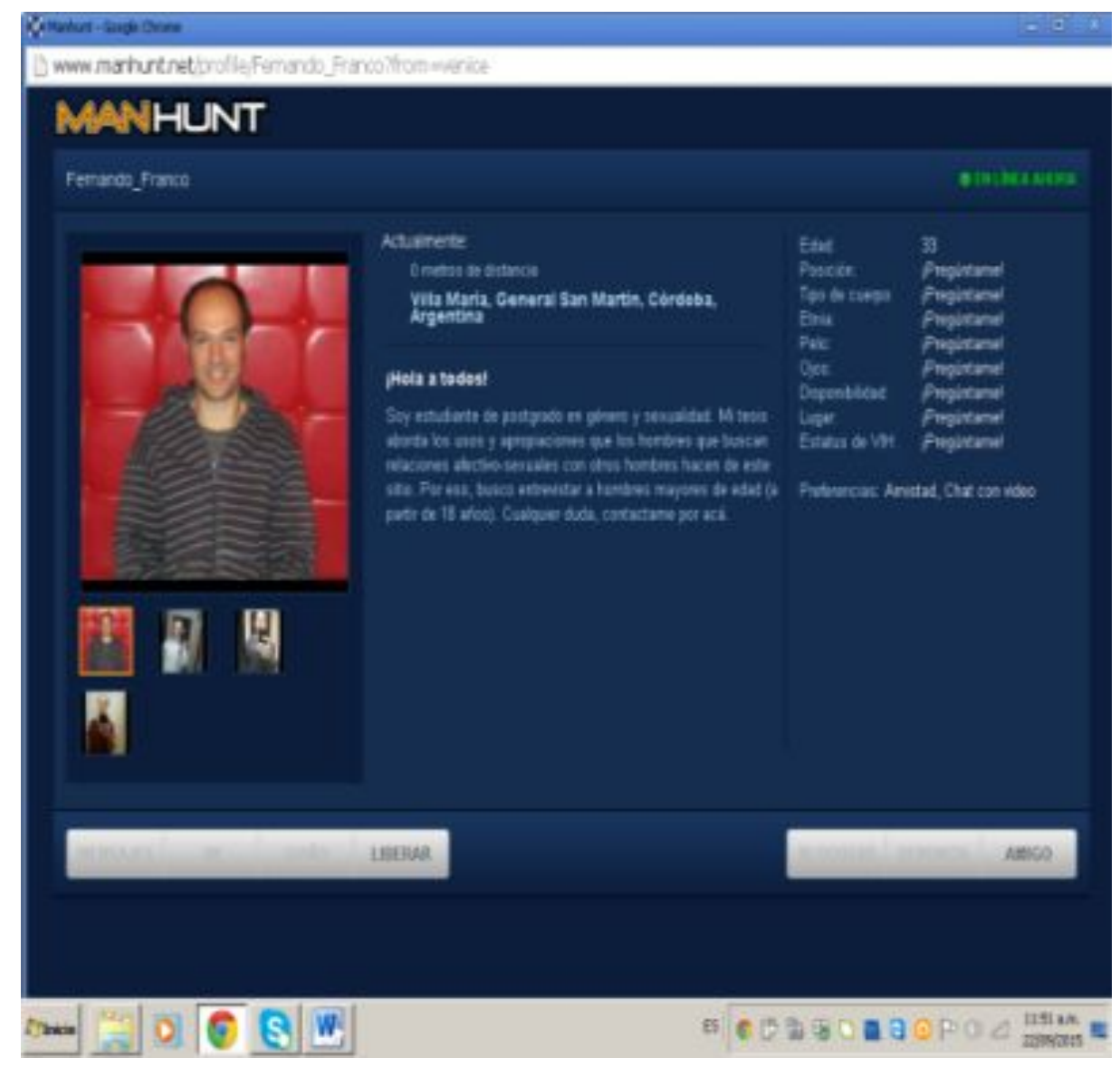

Figura 1. Captura de pantalla del sitio web manhunt.net

Mi estrategia consistió básicamente en conectarme al sitio en diferentes días y horarios y permanecer a la espera de que algún usuario "curioso" me enviara un guiño o iniciara una 

Deseos pixelados - sociabilidad homoerótica masculina en villa maría y la región (Córdoba,
Argentina) a través de manhunt.net

interacción a través del IM (instant message), la herramienta que permite chatear utilizando simultáneamente las cámaras web. Percibí que casi la totalidad de la interacción que ocurre en el sitio tiene lugar cuando los usuarios están en línea (es sumamente inusual que los usuarios envíen mensajes o guiños a otros usuarios cuando no los encuentran conectados).

Cada vez que recibía un guiño, mi respuesta era la siguiente: "Gracias por tu guiño. Por favor, lee mi perfil. Si querés colaborar conmigo, agregame a skype: Fernando_Franco ${ }^{4}$. Saludos." No fueron muchos los usuarios que decidieron participar del estudio (teniendo en cuenta el ratio solicitudes de skype/guiños recibidos). Sin embargo, durante los meses en que desarrollé el trabajo de campo (de agosto a diciembre de 2014) he reunido información realmente valiosa. ¿Cuántos usuarios entrevisté bajo esta modalidad? Seis fueron los usuarios que se prestaron a conversar conmigo mediante el chat de manhunt o skype. De todas las sesiones de chat que mantuve, la abrumadora mayoría las concentró Daniel, con quien conversé a lo largo de 15 días (aproximadamente), desde 15 minutos hasta 1 hora y media, en cada sesión. Además de las entrevistas en línea, pude realizar 21 entrevistas semiestructuradas (sólo 2 de ellas fueron realizadas a través del sistema de llamada que ofrece skype).

Para complementar la recopilación de las manifestaciones verbales (en archivos de audio) y escritas (en archivos de texto) de mis interlocutores, me propuse relevar perfiles de usuario localizados en Villa María (pude constatar que algunos usuarios que residen en localidades más pequeñas prefieren definir su ubicación en Villa María aunque no se trate de su domicilio real). Antes del año 2013, manhunt brindaba una lista de posibles ubicaciones geográficas. Al tratarse de un sitio diseñado para un público global, cuando el usuario se registraba debía indicar donde residía. Esto lo hacía seleccionando primero el país y luego la provincia o estado. Una vez hecho esto, el software brindaba un listado de localidades, usualmente las más pobladas dentro de la provincia.

\footnotetext{
${ }^{4}$ Decidí utilizar mis nombres verdaderos ya que muchos usuarios del sitio (especialmente los villamarienses) me identificarían a partir de las fotos de cara exhibidas en el perfil. Por lo tanto, no tenía el menor sentido escoger nombres alternativos. Además, me parecía conveniente que ambos nombres (en manhunt y skype) coincidieran, para evitar confusiones y preguntas innecesarias. En función de mi experiencia previa en salas de chat, decidí no utilizar nombres tales como "investigador" o "sociólogo" porque podrían disuadir a muchos usuarios de interactuar conmigo por desconocimiento de mis intenciones (si me nombraba como "investigador", existía la probabilidad de ser asimilado a un policía y si lo hacía como "sociólogo", quizás muchos no iban a comprender que pretendía ya que, según pude constatar a lo largo del cursado de mi carrera de grado, la sociología no está representada en los imaginarios populares con la misma nitidez que carreras tradicionales tales como abogacía, medicina o contador público. De más está decir que todos aquellos nombres de usuario que pudieran contener connotaciones eróticas estaban descartados. Presentarme como Fernando_Franco resultó ser la alternativa más "neutral" para entrar en el campo).
} 
Para Córdoba (si mal no recuerdo), las opciones eran: la ciudad de Córdoba, Río Cuarto, Villa María, San Francisco, etc. Es probable que los usuarios que residían en municipios de menor tamaño poblacional hayan escogido la localidad más próxima a su domicilio. Asimismo, muchos usuarios optaban por registrarse en Villa María debido a la mayor cantidad de perfiles radicados allí, además, de este modo reducían las probabilidades de “cruzarse” con algún vecino o conocido. La selección de perfiles siguió un criterio aleatorio, descartando perfiles muy incompletos (es decir, carentes de imágenes y mensaje de presentación). De este modo, almacené 90 perfiles de usuario. Con posterioridad a dicho almacenamiento, elaboré una tabla que constaba de 5 columnas: nombre de usuario, edad y resumen del mensaje de presentación.

\section{Caracterización del espacio urbano donde se asienta la investigación}

Decidí radicar mi trabajo empírico en la localidad de Villa María, cabecera de uno de los 26 departamentos en que se divide administrativamente la provincia, el departamento General San Martín, y se localiza a unos $140 \mathrm{~km}$ al sudeste de la ciudad de Córdoba, capital de la provincia homónima. Con una población aproximada de 80.000 habitantes, es el municipio más poblado del departamento y el tercero más poblado de la provincia. Para poder dimensionar este dato, es preciso tener presente que la provincia cuenta con un total de 3.308.876 habitantes, de los cuales el $40 \%$ reside en la capital. Con una población de 158.298 habitantes, el segundo lugar de la lista lo ocupa Río Cuarto ${ }^{5}$.

Uno de los principales factores que contribuyó a que decidiera situar mi investigación en dicho contexto geográfico fue la constatación de una relativa ausencia de producciones académicas sobre homosexualidades masculinas en las denominadas áreas no metropolitanas (me refiero al caso argentino). En lo que respecta puntualmente a la intersección entre masculinidades homosexuales y uso de medios digitales, sobresale la etnografía del antropólogo colombiano Sigifredo Leal Guerrero (2011) sobre el ejercicio de las aphrodisia entre hombres de Buenos Aires en dos portales web (Gay.com y Gaydar).

Como se explicita en el subtítulo de este texto, el área geográfica en que se sitúa mi trabajo de campo se extiende más allá de los límites de la localidad de Villa María. Esto se debe en parte a los motivos que señalé anteriormente y que tienen que ver con la dinámica que

\footnotetext{
${ }^{5}$ La distribución demográfica es sumamente inequitativa en el territorio cordobés si consideramos que sobre un total de 427 áreas de gobierno local (250 municipios y 177 comunas), los 10 municipios más poblados concentran el $57 \%$ de los habitantes.
} 


\section{Deseos pixelados - sociabilidad homoerótica masculina en villa maría y la región (Córdoba, Argentina) a través de manhunt.net}

tan bien describe Padilha (2015) para su campo: ante el exiguo número de perfiles en determinadas localidades y el deseo de experimentar los encuentros homoeróticos con "sigilo" y "discreción”, los usuarios prefieren movilizarse hacia el centro urbano más poblado, y más cercano a su hogar. Teniendo en cuenta que el servicio de transporte público tiene opciones bastante limitadas para acceder a las poblaciones de menor porte que Villa María (y viceversa $^{6}$, la movilidad interurbana requiere que los usuarios dispongan de un auto. No puede desconocerse que dicha movilidad ha sido favorecida recientemente por la construcción de la autopista Córdoba-Rosario, una importante obra de infraestructura inaugurada en el año 2010 , con un trazado de $312 \mathrm{~km}$ y una inversión cercana a los \$ 3.200 millones.

Asentada en una de las regiones más económicamente productivas del país, en Villa María confluyen varias rutas nacionales y provinciales. El informe publicado por el Instituto de Estudios sobre la Realidad Argentina y Latinoamericana (IERAL) perteneciente a Fundación Mediterránea ${ }^{7}$ afirma que debido al desarrollo de la ganadería y a la ingente producción de cereales y oleaginosas (soja, trigo, maíz, girasol, avena, centeno, cebada), la ciudad ha devenido un importante centro económico subregional donde han proliferado industrias y servicios vinculados con tales actividades (agromecánica y agroquímicos, por ejemplo). Algo que no podemos dejar de mencionar es el peso que adquiere la producción de lácteos, siendo Villa María el centro de una de las principales cuencas lecheras del país. Asimismo, como señala el mencionado informe, la actividad comercial minorista y los servicios se constituyen en los sectores económicos con mayor preponderancia en la ciudad.

Según el informe publicado por el Observatorio Integral de la Región, en el aglomerado Villa María-Villa Nueva (integrado por una población levemente superior a los 100.000 habitantes), en el tercer trimestre de 2013, la tasa de empleo (población ocupada/población total) registró un $61 \%$. La distribución de las ocupaciones por rama de actividad para aquellas personas de 14 años o más arrojaron las siguientes cifras:

- Comercio mayorista y minorista - reparación de vehículos: $24 \%$.

- Industrias manufactureras: $13 \%$.

- Construcción: $12 \%$.

- Actividades domésticas productivas: $7 \%$.

\footnotetext{
${ }^{6}$ Sirva la siguiente situación de ejemplo: para realizar una de mis entrevistas en la vivienda del entrevistado, ubicada a unos $60 \mathrm{~km}$ de Villa María, tuve que viajar en un vehículo tipo furgoneta, comúnmente denominado "Trafic" o "Combi" con capacidad para 10-12 pasajeros (aproximadamente). Este servicio de traslado era brindado por un particular, y tenía una frecuencia de 2 veces al día, dos días a la semana. El vehículo era conducido por un chofer contratado por el propietario y partía desde la plaza más céntrica de Villa María.

${ }^{7}$ Véase Informe de Localización: Villa María (Fundación Mediterránea, Instituto de Estudios Económicos sobre la Realidad Argentina y Latinoamericana, Análisis y Herramientas para las PYMES, s/f).
} 
- Enseñanza: $7 \%$.

- Transporte y almacenamiento: $6 \%$.

- Administración pública y defensa; planes de seguridad social de afiliación obligatoria: $6 \%$.

- Otras (servicios administrativos, financieros, inmobiliarios, actividades agropecuarias, actividades artísticas, etc.): $25 \%$.

Si desagregamos la masa laboral en 4 categorías ocupacionales $\left(1^{\circ}\right.$ patrón o empleador, $2^{\circ}$ trabajador cuentapropista, $3^{\circ}$ obrero o empleado, $4^{\circ}$ otra), la mayor parte de la población del aglomerado considerado pertenece a la tercera categoría (con un guarismo estimado entre el $60-70 \%)$.

Como vimos previamente, Villa María es una ciudad con unos 80.000 habitantes. Si bien no disponemos de estadísticas al respecto, es posible afirmar que la mayor parte de ellos adscribe al culto católico apostólico romano ${ }^{8}$ por tratarse de la tradición mayoritaria en el país. Algunas de las instituciones educativas más prestigiosas son confesionales y educan a su alumnado en los preceptos de dicho culto. Sin embargo, otros cultos que tienen presencia son: el evangelismo, el judaísmo, los testigos de Jehová, la iglesia universal del reino de dios, etc.

En una sociedad con un imaginario donde la ruralidad tiene una presencia significativa, uno de los eventos sociales más concurridos y representativos de la identidad local es el Festival Nacional de Peñas, que se realiza todos los años en el mes de febrero. Durante el mismo, se sirven comidas regionales típicas, se arman ferias de artesanos y se asiste a espectáculos de danza, música folklórica y popular. En los últimos años, a medida que cobra peso en la escena nacional y latinoamericana, la grilla de artistas que participan se ha diversificado, abarcando una pluralidad de géneros musicales (cuarteto, tango, pop latino, rock, blues, cumbia). Esta estrategia de "expansión" ha sido implementada vigorosamente por la gestión actual de gobierno, a cargo del intendente Eduardo Accastello, con el propósito de atraer a públicos provenientes de otras provincias y países.

\section{Una visita al pasado reciente}

\footnotetext{
8 En Argentina ninguna religión reviste el carácter de oficial. La Constitución Nacional, en su artículo $2^{\circ}$, prescribe el sostenimiento del culto católico. Por tal motivo, la iglesia católica apostólica romana cuenta con un status jurídico diferenciado, a tal punto que recibe financiamiento estatal.
} 

Deseos pixelados - sociabilidad homoerótica masculina en villa maría y la región (Córdoba,
Argentina) a través de manhunt.net

Hacia finales de la década de 1990 se produjo la llegada de internet a Villa María de la mano de las compañías telefónicas, Telecom y Telefónica. No era habitual en ese entonces el acceso a la red de redes desde el hogar sino a través de los populares locutorios o cibercafés. Teniendo en cuenta que las computadoras estaban a la vista de todos, el acceso a sitios con contenidos sexuales no podía realizarse por el control que ejercían las miradas de los dueños, encargados u ocasionales clientes de tales establecimientos. A medida que nos introducimos en el nuevo milenio, aumentó el número de compañías que proveían el servicio de acceso a internet. El aumento de la competencia abarató el precio del servicio, lo cual en consonancia con las transformaciones tecnológicas que mejoraron la calidad del mismo (en particular la velocidad de navegación), se produjo un considerable aumento en la cantidad de hogares con acceso a internet. Hacia finales de la década en cuestión el acceso a internet utilizaba un modem dial-up, cuya conexión fallaba en numerosas oportunidades y la recepción/transmisión de datos era lenta y restringida (la tarifa se aplicaba en función de la cantidad de megabytes consumidos mensualmente). Durante la primera década de 2000 comenzó a popularizarse el servicio de acceso a internet denominado "banda ancha", el cual mejoró significativamente la calidad del servicio, al posibilitar una mayor velocidad de navegación y una tarifa fija o plana (es decir, el abonado pagaba un monto constante, pudiendo hacer uso del servicio de recepción/transmisión de datos durante todo el tiempo que quisiera).

Según los informes presentados por el Instituto Nacional de Estadísticas y Censos (INDEC), la cantidad de hogares que acceden a internet viene creciendo a pasos agigantados en la última década: mientras que en marzo de 2004 el número total de accesos no llegaba a 2.000.000, en marzo de 2014 superó los $12.000 .000^{9}$. Replicando la distribución poblacional característica de Argentina, la ciudad de Buenos Aires y las provincias de Buenos Aires, Córdoba, Santa Fe y Mendoza concentran alrededor del 77\% de los usuarios hogareños de internet.

En la primera etapa de acceso a internet, la interacción entre hombres con fines sexoafectivos se realizaba a través de las salas de chat. El siguiente fragmento de entrevista da cuenta del escenario que se vivía en ese entonces.

F: ¿Cómo se conocieron?

D: Por chat, es mi único medio de conocer gente, quizás.

F: ¿A partir de cuándo vos empezaste a chatear para conocer gente aproximadamente?

\footnotetext{
9 Véanse los siguientes informes: “Accesos a Internet. Datos provisorios" (2005) y "Accesos a Internet. Primer Trimestre 2014” (2014) (INDEC).
} 
D: Cuando llegaron los cibers a [mi pueblo], en el 2000.

F: Sí, puede ser, acá más o menos también para esa fecha, quizás antes ya había servicio de internet.

D: Lo que pasa es que allá llegó por dial-up. Se llamaba por teléfono, un servicio muy, muy precario. Y ahí yo empecé a conocer gente.

F: Estaría bueno que empezaras a narrar eso, cómo vos te empezaste a vincular por el chat con gente como vos...

D: Y yo creo que entré buscando conocer gente y que en ese entonces había gente de Villa María nomás...

F: En el 2000, entonces hace 12 años. Vos tenías... ¿cuánto tenés ahora?

D: Tengo 35.

F: 35, claro. Entonces estamos hablando más atrás del 2000.

D: Sí, 98-2000...Ponele a partir del 2000. Claro, hace 12 años.

Cerramos en el 2000, cerramos ahí.

F: Hace 12 años, vos tenías 23 aproximadamente.

D: Sí, 22, 23.

F: 22, 23. Ehh, ¿qué chat usabas y qué experiencias tuviste? Porque también a veces se cuentan experiencias negativas en el chat. ¿Vos invitabas gente a tu casa o los citabas...?

D: No, me venía a Villa María [risas]. No, no, yo no llevaba a nadie a casa.

$\mathrm{F}:$ ¿Vos vivías con tu familia?

D: Con mi familia, sí.

F: Bueno, pero a veces también se ponen de acuerdo y se juntan en algún lugar público.

D: Sí, yo empecé chateando en arnet.

F: El chat de arnet...

D: El famoso chat de arnet.

F: ¿Por qué ese chat? ¿Por qué no otros chats?

D: No sé si llegó por recomendación o porque investigando llegué a ese... mientras todos mis amigos chateaban en el Latin Chat yo entraba a arnet que a su vez me acuerdo patente que se podía entrar a 2 salas a la vez. Entraba a una que era la sala de Córdoba y a otra que era la sala Gay. Cuando alguien se acercaba habría la sala de Córdoba, porque viste que estaba en un ciber, y por la otra tiraba para conocer a alguien de acá de Villa María, generalmente.

F: ¿Vos ibas a un ciber?

D: A un ciber, me pasaba las horas ahí. Es más, una vez hicieron un juego que a mayor cantidad de horas que iba sumando, te ganas un premio pero me lo gané [no se entiende] lejos, pero muy lejos por la cantidad de horas que me pasaba.

F: ¿Cuántas horas por semana aproximadamente?

D: Y qué sé yo calculale que salía de laburar a las 12 de la radio, me iba hasta las 2 de la tarde que cerraba el ciber, a lo mejor a las 4 se abría y ya estaba de nuevo ahí hasta las 6,7 de la tarde; trabajaba, por lo tanto no era un problema pagarme las horas de internet.

(Entrevista con David, gay, 35 años) 
Tal como relata David, un hombre autoidentificado como gay, soltero, de profesión locutor, residente de una pequeña localidad ubicada a unos $40 \mathrm{~km}$ de Villa María, el chat de arnet $^{10}$ fue uno de los principales sitios web donde confluían aquellos hombres con fantasías homoeróticas hacia finales de la década de los 90. Por sus limitaciones tecnológicas, a saber, la falta de funcionalidades relativas a la transmisión de imágenes/vídeo, los usuarios debían solicitar descripciones sobre las características físicas antes de concertar un encuentro o, lo que resultaba mucho más habitual, utilizar el servicio de mensajería instantánea de Microsoft, Messenger, software que les permitía visualizar fotografías y vídeo (además de conversar por micrófono).

A lo largo de mi investigación el chat de arnet me brindó contactos para entrevistar y una de mis primeras aproximaciones a los sentidos construidos por los hombres que buscaban encuentros homoeróticos en mi ciudad y zona. A mediados del año 2013 el sitio, que desde hacía varios meses tenía problemas tecnológicos para funcionar, fue dado de baja. Bastante avanzada la primera década del siglo XXI comenzó a popularizarse entre los gays de Villa María, manhunt.net, un sitio web diseñado por estadounidenses y lanzado en 2001. En el siguiente apartado, me ocupo de presentar dicho portal.

\section{Logueándonos a manhunt.net}

Como señala Melhado (2014), el sitio pertenece a la compañía Online Buddies, Inc., cuya sede se encuentra en Cambridge, estado de Massachusetts, Estados Unidos. Fue fundada por Jonathan Crutchley y Larry Basile con el propósito de "conectar a la comunidad gay durante el ascenso de las citas en línea" ${ }^{11}$. De acuerdo al ranking Alexa ${ }^{12}$, el sitio ocupa el puesto número 3.927 en el tráfico global de información (actualizado a marzo de 2015).

A pesar de tratarse de una tecnología que ha sido diseñada pensando globalmente traigo a colación la advertencia de Castells (citado en Melhado, 2014, p. 20) con respecto a la especificidad cultural que acarrea, la cual no es posible soslayar a la hora de realizar un

\footnotetext{
${ }^{10}$ Arnet es el nombre de una de las pocas empresas que provee el servicio de acceso a internet en mi país. Es posible conjeturar que la popularidad del chat de arnet en mi ciudad (y zona) se haya debido a que pertenece a la empresa de telecomunicaciones Telecom, la cual acaparó el mercado local tras la privatización de la empresa estatal ENTel durante el auge neoliberal de la década de los 90. Junto con Telefónica se distribuyeron el servicio de telefonía en Argentina (Telecom alcanzó una participación del 54 \% y Telefónica del $44 \%$ ) cubriendo cada una el $100 \%$ del mercado en sus respectivas áreas geográficas de exclusividad. Véase FORCINITO, Karina (s/f).

${ }^{11}$ Extraído textualmente del sitio web de la compañía Online Buddies. La traducción es mía.

${ }^{12}$ Alexa Traffic Rank aporta una medición de la popularidad de los sitios web basándose en la combinación de dos factores: la cantidad de visitantes únicos que tiene un sitio en un día determinado y la cantidad total de páginas vistas, es decir, pedidos de URL que recibe (uniform resource locator-localizador uniforme de recurso-, es decir la dirección que identifica a los sitios web). El sitio que obtiene los valores más altos de la conjunción de visitantes únicos y páginas vistas ocupa el puesto 1. Más detalles en página web de Alexa.
} 
análisis perspicaz. No solamente es posible afirmar la inexistencia de una tecnología desprovista de las marcas provenientes del contexto socio-cultural en el cual fue concebida sino también la inexistencia de un usuario genérico. En este sentido, uno de los objetivos de mi indagación es, justamente, dar cuenta del modo en que esta tecnología es apropiada por los hombres del contexto empírico que he recortado (localidades del interior de la provincia de Córdoba, tomando como base Villa María).

El artículo de Miskolci (2013), la tesina de grado de Melhado (2014) y la tesis de Maestría de Padilha (2015) constituyen sendos antecedentes en el campo de los estudios de las homosexualidades masculinas y los medios digitales, pero sobre todo por sus reflexiones acerca del carácter situado del uso de tales medios, dimensión que pareciera no haber sido debidamente problematizada por Leal Guerrero (2011) y Zago (2013) en sus respectivas investigaciones. En contraposición a estas últimas posturas, Mowlabocus (invocando a Shaw) nos recuerda que:

[D]esde el inicio, al menos algunos de los trabajos sobre la cultura digital de los varones homosexuales ha reconocido que lo digital no está separado de otras esferas de la vida homosexual, sino que, de hecho, es el resultado de las subculturas homosexuales masculinas local, nacional e internacional, a la vez que permanece arraigado a ellas $^{13}$. (2010, p. 7).

Me interesa resaltar, muy especialmente, que un entendimiento de la cultura digital como situada localmente no implica desatender las conexiones de dicha cultura con otros espacios (lo nacional y lo global).

Para utilizar el sitio es preciso crear un perfil, brindando un nombre de usuario y una contraseña. Son múltiples los campos que el usuario puede completar para dar una descripción de su cuerpo: edad, altura, tipo de cuerpo ("atlético", "normal", "oso", “fisicoculturista”, “gordito", “grande”, “muscular", “delgado", "nadador”, “definido”), tipo de pelo (“calvo", "negro", "rubio", "rapado", "rubio oscuro", “castaño oscuro", "gris”, "castaño claro", “con entradas", "pelirrojo", “canoso", "pelo corto”), ojos (“negro", “azul”, "café", "verde", "gris", “avellana”), etnia (“asiático", "negro”, "hindú”, "hispano”, “árabe”, "mestizo", “indígena”, “otro", “sudasiático", "blanco"), tamaño del pene (largo, circunferencia -en cms. o pulgadas-), si fue o no circuncidado, posición ("pasivo", “versátil/pasivo", "sólo masturbar", "sólo oral”, “activo", "versátil/activo", "versátil”) y estatus de HIV ("no sé”, "negativo", "positivo", “sin responder”). El usuario puede optar por

${ }^{13}$ La traducción me pertenece. 


\section{Deseos pixelados - sociabilidad homoerótica masculina en villa maría y la región (Córdoba, Argentina) a través de manhunt.net}

dejar esos campos sin completar, los cuales serán exhibidos en su perfil con la leyenda: "pregúntame".

El sitio también posibilita al usuario incluir un mensaje de presentación/explicación de su propósito allí, indicar su disponibilidad (“después del trabajo”, "siempre”, "ya vuelvo”, "en Chat”, "Más tarde”, "No busco”, “Ahora no”, “Ahora mismo!”, “Sugiere algo”, "Entre semana", "Fin de semana") y si cuenta o no con lugar para desarrollar los encuentros ("Carro", "Vienes o voy", "Hotel”, "Lugar público", "En mi lugar”, "Sexo en público”, "En tu lugar”).

Por último, hay 35 opciones de preferencias codificadas por los diseñadores del sitio. Al hacer clic en los casilleros correspondientes, el usuario puede comunicar a quienes visualicen su perfil qué prácticas sexuales ("sexo oral”, "sexo anal”, "bondage”, "sadomasoquismo", "voyeurismo", etc.) y orientaciones sexuales ("hetero/bi") prefiere o el tipo de vínculo que desea entablar ("amigo sexual", "sin compromisos", "citas", "pareja o novio", "amistad").

Durante el período en que formo parte de los usuarios activos del sitio he observado la incorporación de 2 nuevas funcionalidades: durante la primera mitad del año 2013 se añadió la función de $<<$ Localización $>>$, que permite al usuario especificar dónde se encuentra (el software, al menos su versión para la computadora, no tiene la capacidad de detectar automáticamente la ubicación); a mediados de 2014, se añadió el tablero, un espacio donde los usuarios pueden realizar publicaciones visibles para todos al estilo de avisos clasificados, diciendo qué buscan, formulando preguntas, expresando opiniones, etc. (he constatado que dicha función está completamente desaprovechada por los usuarios de Villa María). El tablero se asemeja bastante al extinto chat de arnet, donde los usuarios circulaban información que consideraban relevante para los miembros del "ambiente gay" (por supuesto, no faltaban ocasiones donde se vertían numerosas injurias, difamaciones y mensajes agresivos hacia otros usuarios).

Indudablemente, una de las funciones más potentes de manhunt.net es su buscador. Gracias a ella, los usuarios pueden hacer visibles los perfiles de aquellos que podrían resultar “elegibles" en la medida en que reúnen la mayor cantidad de características consideradas deseables. Así, un usuario puede filtrar perfiles de acuerdo a la localización (ingresando un radio expresado en kilómetros desde la localidad donde se encuentra), un intervalo de edad, altura, largo y grueso del pene, tipo de cuerpo, posición, y todas las características físicas y demás datos almacenados (disponibilidad, lugar, preferencias). Siguiendo a Miskolci (2013), esta posibilidad de buscar activamente "compañeros sexo-afectivos" puede interpretarse como 
un comportamiento virilizante, que se contrapone a las atribuciones de "afeminamiento" que tradicionalmente han tenido como blanco a los varones homosexuales.

El software presenta los resultados de las búsquedas ordenando los perfiles que se ajustan al criterio ingresado desde el más cercano al lugar de residencia marcado por el usuario, indicando la distancia en metros y kilómetros.

Manhunt, (en español, cacería de hombre) es un sitio diseñado para que los hombres puedan conectarse entre sí ya sea que busquen hacer amigos, conocer a potenciales parejas o satisfacer deseos sexuales con acompañantes ocasionales (entre otros posibles usos). Los usuarios, en su mayoría, así lo entienden. Esto surge del análisis de los mensajes de presentación que los usuarios redactan en sus perfiles. De los 90 casos seleccionados (entre 18 y 52 años, con un promedio de edad cercano a los 30 años), 59 describen qué tipo de vínculo buscan establecer. Identifiqué tres tipos:

1) Aquellos que quieren "conocer a alguien para ver qué onda, qué surge o ver qué se da" (27 perfiles).

2) Aquellos que buscan una relación "seria" o "más que pasajera" (4 perfiles).

3) Aquellos que buscan sólo "pasarla bien, disfrutar el momento, sexo casual, sin compromisos, sexo y nada más" (28 perfiles).

A pesar de tener múltiples usos, no puede desconocerse que la última forma de relación pareciera ser la más incentivada por el sitio. Por ejemplo, hace unos meses, mientras se celebraba el Día de San Valentín ${ }^{14}$, el 14 de febrero, un banner hizo su aparición con la leyenda: "Menos San Valentín y más cacería". Uno de mis interlocutores, Antonio, expresaba del siguiente modo qué utilidad le asigna a la página:

F: vos qué buscás acá? [“Acá” se refiere a la página manhunt.]

A: sexo

F: y conseguís lo que buscás?

A: si si

F: a qué te parece que se debe eso?

A: a que encuentre lo que busco?

F: sí

A: es como cualquier otra cosa, normal

(...)

\footnotetext{
${ }^{14}$ Aunque podría tratarse de una tradición no típica de los argentinos, en la última década ha incrementado su relevancia. Podemos entender la incorporación de este festejo como una forma que tiene nuestra cultura de atribuirle importancia a las relaciones de pareja fundadas en el compromiso y el amor recíproco.
} 


\section{Deseos pixelados - sociabilidad homoerótica masculina en villa maría y la región (Córdoba, Argentina) a través de manhunt.net}

A: si quiero una máquina de fotos usada entro a alamaula.com ${ }^{15} \ldots$ si quiero sexo entro a manhunt

(Chat en manhunt con Antonio, 27 años, bisexual, residente en Villa María).

En Intimidades congeladas, Illouz (2007) analiza el fenómeno de los sitios web que asisten en la búsqueda de parejas estables o con fines "serios". Si bien manhunt no es utilizado prioritariamente con esa finalidad, es posible extrapolar algunas de las observaciones que la socióloga ha realizado en relación a tales sitios:

Internet literalmente estructura la búsqueda de pareja como un mercado, para ser más exactos, formaliza la búsqueda de pareja como una transacción económica: transforma el yo en un producto envasado que compite con otros en un mercado abierto regulado por la ley de la oferta y la demanda; hace que el encuentro sea el resultado de un conjunto de preferencias más o menos estables; hace que el proceso de búsqueda comprenda el problema de la eficiencia; estructura los encuentros como nichos de mercado; asigna un valor económico (más o menos) fijo a los perfiles (es decir, a las personas) y hace que la gente se preocupe precisamente por su valor en ese mercado estructurado y por mejorar su posición en el mismo. (2007: pp. 188189)

No es necesario realizar una observación demasiado profunda para percibir la similitud entre manhunt y cualquier sitio destinado a la compra-venta de cualquier tipo de bienes o mercaderías. Si tomamos la web de cualquier empresa del rubro electrodomésticos/electrónica, las coincidencias resultan demasiado evidentes. Para empezar, los productos están presentados a través de imágenes y descripciones que detallan sus características principales. En segundo lugar, el usuario puede ejecutar la búsqueda de productos específicos de acuerdo a criterios de filtro (categoría de producto, subcategoría, características del producto, rango de precio, etc.). Por último, el usuario puede calcular cuál es el costo involucrado en el acceso al producto (más allá de que en manhunt los perfiles no explicitan un precio -excepto el que es negociado en privado con los usuarios que ofrecen "discretamente" sus servicios sexuales-, el sitio informa la distancia que separa a los usuarios así como las empresas de electrodomésticos informan si los productos están disponibles en alguna sucursal cercana al domicilio del comprador).

Indudablemente, la analogía mercantil cobra absoluta relevancia para comprender el funcionamiento de manhunt. Zago (2013), uno de los estudiosos del sitio, nos habla del

\footnotetext{
${ }^{15}$ Alamaula.com es una red de sitios de avisos clasificados de diferentes tipos de bienes y servicios orientado a usuarios de América Latina.
} 
“mercado de la carne”. Así como Antonio nos manifestaba su acuerdo con la finalidad para la cual fue diseñado el sitio, Mariano, un hombre autoidentificado como gay, 46 años, soltero, de profesión docente de escuela media, residente en una pequeña localidad ubicada a unos $60 \mathrm{~km}$ al sur de Villa María es consciente de la cosificación a la cual se encuentra sometido:

F: ¿Cómo definirías vos tu rol sexual? Bueno, ahí dice versátil/pasivo... [“Ahí” se refiere al perfil de manhunt que estábamos observando en la situación de entrevista.]

M: Sí...

F: Versátil... ¿a qué te referís con versátil?

M: No, a versátil lo agregué porque viste... como que pasivo, van a decir, "eehh”... ¡no conseguís nunca nada! ¿Y ahora la onda cuál es? Versátil...

$\mathrm{F}:$ ¿Por qué decís que pasivo...?

M: No, pasivo, no, es raro conseguir...

F: O sea, vos decís que buscan más al versátil...

M: Versátil.

F: Versátil. O sea, que cumple un rol de activo y pasivo.

M: Claro. Sí, porque ahora la onda es esa. ¿Viste que los chicos más jóvenes son así?

(...)

F: Así que vos decís que versátil hoy en día...

M: Es como que suena como un poquito más atractivo. Es una cuestión de marketing.

(Entrevista con Mariano, 46 años)

Mariano se sabe imbuido de la implacable lógica de la competencia. Como afirma Illouz (2007), los usuarios están compelidos a competir por la atención de la audiencia. Cuando Mariano se presenta en su perfil como "versátil/pasivo" cuando en realidad sólo es "pasivo", está intentando posicionarse por encima de otros usuarios, sus potenciales competidores. Definir quiénes integran ese conjunto no es para nada sencillo, pero a prima facie, podríamos incluir allí a todos los hombres de edades aproximadas.

A partir de lo que pude percibir en mi campo de investigación, la categoría "pasivo" des-masculiniza a quien la porta. No son pocos los usuarios que prefieren, al igual que Mariano, presentarse como "versátiles/pasivos", "versátiles" o directamente esquivar cualquier rótulo que implique su desvío del patrón macho-masculino-activo seleccionando la opción "pregúntame", lo cual les permite abrir el juego de la negociación de las prácticas sexuales. En fin, lo que se busca movilizar en la seducción en línea es la valorizada masculinidad, que se materializa en esa capacidad de "hacer de hombre". 

Deseos pixelados - sociabilidad homoerótica masculina en villa maría y la región (Córdoba,
Argentina) a través de manhunt.net

En su análisis sobre la utilización de medios digitales por parte de hombres que buscan encuentros homosexuales en la ciudad de San Pablo, Brasil, Miskolci (2013) propone un régimen erótico en línea ${ }^{16}$ plasmado en un conjunto de diagramas que muestran las características ideales más buscadas, las aceptables y las rechazadas en relación a: apariencia física, origen socio-económico y comportamiento/valores. Las palabras de Mariano engarzan a la perfección con el ordenamiento jerárquico de los roles sexuales en dicho régimen: ser un sujeto pasivo implica ser menos que un sujeto versátil, ser un sujeto versátil implica ser menos que un sujeto activo.

Tal como afirmé anteriormente, la versatilidad es preferible a la pasividad porque está asociada con una conducta "potencialmente" más viril, y como he podido constatar, el afeminamiento es un rasgo ampliamente rechazado por los usuarios de manhunt (es probable que los usuarios deduzcan que un varón performa una masculinidad más próxima a la masculinidad hegemónica si se define como versátil en vez de pasivo a secas). Ninguno de los 90 perfiles analizados incluye el adjetivo "afeminado" como atributo del usuario. Los que eligen describirse a sí mismos (a partir de sus rasgos físicos o psicológicos), lo hacen afirmando ser "masculinos" o "machos". Algunos explícitamente rechazan cualquier posibilidad de interacción con sujetos "afeminados", "locas" o que tengan "plumas". Como señala uno de mis entrevistados, a la hora de encontrarse con un compañero sexual ocasional, la invisibilidad es un bien altamente valorado.

F:¿Por qué crees que se da ese rechazo, discriminación hacia los gays más afeminados? Porque es una constante que se encuentra en el chat, la búsqueda de gente de aspecto muy masculino.

I: Sí, yo creo que lo que pasa es que en el chat es una cuestión pura y exclusivamente para tener sexo, entonces el que quiere tener sexo, no quiere tener más que eso, entonces no se quiere encontrar en la calle con una loca. De última, mientras pase más desapercibido, mejor. Por eso te digo, entonces no es solamente hacer amistad únicamente; casi todos... hay gente que no quiere tener amistad con gente gay llamativa por eso, porque le da vergüenza, qué sé yo, pero me parece que es por una cuestión del sexo, o sea no quieren que ni te vean, o sea a mí me ha pasado de tener garches donde uyy, medio como que me dan a entender "fijate que no te vea nadie que entraste o fijate que no haya nadie en la calle cuando abrís la puerta" o cuando caen a tu casa miran para todos lados pero eso para mí es toda una persecución personal. (Iván, 31 años, gay, residente en Villa María)

\footnotetext{
16 Miskolci postula que pensemos los regímenes eróticos en términos históricos, culturalmente variables y asentados en intereses colectivos (en vez de concebirlos como sistemas naturales dados que conectan a los individuos sobre la base de intereses íntimos). (2013, p. 58).
} 


\section{Cuerpos (in)deseables: el régimen erótico en línea}

En Estigma. La identidad deteriorada, Goffman asevera que:

Por ejemplo, según el consenso general, en Estados Unidos, el único hombre que no tiene que avergonzarse de nada es un joven casado, padre de familia, blanco, urbano, norteño, heterosexual, protestante, que recibió educación superior, tiene un buen empleo, aspecto, peso y altura adecuados y un reciente triunfo en los deportes. (1998, p. 150)

Me parece que esta cita tiene un enorme potencial para comprender que, analógicamente, según el consenso general, en manhunt.net el único hombre que no tiene que avergonzarse de nada es un joven blanco, de rostro agradable, alto, de contextura física atlética/musculosa, bien dotado, con gestos y ademanes viriles, con una adecuada cantidad de vello corporal distribuido en su torso, antebrazos y piernas, con cabellos en su cabeza, un timbre de voz grave, y un rol sexual activo. Conforme a mis propias observaciones y a los dichos de mis interlocutores, este perfil sería el más valorizado por los usuarios de manhunt.net localizados en el espacio geográfico delimitado.

$\mathrm{M}:$... es como que se ponen demasiados requisitos para poder llegar a conocerse.

F: ¿Por ejemplo?

$\mathrm{M}$ : Y que tiene que ser alto, lindo, marcado, ojos claros...

$\mathrm{F}$ : ¿Eso es lo que vos notás que piden?

M: Sí, Sí. Y eso es una desventaja porque si vos querés conocer a alguien, lo conocés, después si surge algo, bien, no surge nada, chau, pero no... si sos alto, ya contás, si estás marcado, contás, si llegás en auto marcás más...

(Entrevista con Mariano, 46 años)

F: Bien, a vos cuáles te parece que son las características que los usuarios valoran de los perfiles de manhunt?

G: cuerpos perfectos, pijas importantes y cerebros semi vacios jajajaj

F: por qué te parece que esto es así?

G: porque lo aclaran en los perfiles. Siempre si tiene buenos cuerpos, piden iguales a ello, siempre me pregunte porque no se compran un espejo jajaja.

(Chat en skype con Genaro, autoidentificado como gay, 55 años)

D: ahora está todo eso de la belleza por favorrr

F: A ver, contame por qué decís ahora????

D: porque hace años no se hablaba de eso de belleza, ahora todos quieren ser un adonis. 
Por favor, cada cual somos como somos. Lo mejor es escuchar el tema "soy como soy"17.

(Chat en manhunt con Daniel, 55 años).

Si bien los "requisitos" que deben llenar los perfiles se refieren primordialmente al cuerpo y a la performance de género, en un segundo plano aparece la cuestión socioeconómica. "Si llegás en auto, marcás más", dice Mariano en relación a las expectativas que los usuarios tienen sobre el capital económico de sus potenciales compañeros sexo-afectivos. Más allá de que poseer un vehículo sea un indicador de capacidad adquisitiva, también podemos interpretar ese requisito en clave de género: el auto está tradicionalmente asociado con el desempeño de la masculinidad hegemónica ya que posibilita a su propietario disponer de autonomía para desplazarse $\mathrm{y}$, simultáneamente, lo viriliza, porque confirma que cuenta con la suficiente destreza, saberes técnicos y coraje para operarlo. Además, el auto puede servir de lugar donde mantener relaciones sexuales.

Otro aspecto sobre el que interesa echar algo de luz es el que introduce Genaro (divorciado de una mujer, padre de 2 hijas, psicólogo social y artista, residente a unos $120 \mathrm{~km}$ de Villa María) cuando manifiesta que aquellos usuarios con "buenos cuerpos" demandan compañeros en idénticas condiciones. Como si se tratara de experimentar el propio cuerpo en otro, estos usuarios dan cuenta de una modalidad de interacción a la que podríamos etiquetar de narcisista. Sabiéndose poseedores de los atributos físicos más codiciados por todos los habitantes del sitio, para ellos, parafraseando a Miskolci (2013; 2014), lo hegemónico y lo similar se vuelven, simultáneamente, eróticos. ¿Cómo adquieren validez estas proposiciones? Lo hegemónico se vuelve erótico porque aquellos usuarios que encarnan atributos físicos valorizados por todos, desean en otros esos mismos atributos (el deseo se vuelve recursivo). Además, lo similar se vuelve erótico porque su deseo se orienta hacia quienes mejor puedan reflejar/copiar su sí mismo. Esta forma de desear se contrapone a la ejercida por aquellos usuarios que sabiéndose carentes de los atributos físicos valorizados, los buscan en otros (cuerpos gordos que desean cuerpos atléticos/musculosos) o erotizan a otros subalternos similares (cuerpos gordos que desean cuerpos gordos).

En consonancia con lo propuesto por Campbell (citado por Mowlabocus), estos datos nos sirven para pensar que la experiencia digital de los varones homosexuales le otorga al cuerpo un protagonismo inusitado: "Lejos de ser un medio de escapar del cuerpo, la interacción en línea constituye un medio para la rearticulación de nuestra relación con el

\footnotetext{
${ }^{17}$ Se refiere a la canción "Soy lo que soy", interpretada por la cantante lesbiana de nacionalidad argentina Sandra Mihanovich.
} 
cuerpo físico." (2010, p. 13). En su libro O amor nos tempos do capitalismo (2011), Illouz nos advierte que, lejos de ser experiencias des-corporizadas, los cuerpos son aspectos fundamentales de las interacciones mediadas digitalmente. Al describir sus características psicológicas y físicas, los usuarios de manhunt realizan, de acuerdo a la socióloga marroquí, una "textualización de sus subjetividades y corporalidades" (práctica heredada de la etapa durante la cual no existían los dispositivos tecnológicos para capturar y transmitir imágenes/vídeos).

A pesar de que no es sencillo establecer cuándo comenzó a utilizarse manhunt.net en Villa María y alrededores (no dispongo de datos sobre el lanzamiento de su versión en español), una estimación basada en los testimonios que he recolectado situarían este inicio en el año 2008 (su popularización mediante el "boca a boca" se habría dado de manera casi simultánea a la ocurrida con las redes sociales "estrellas" de la internet Facebook y Twitter).

Manhunt.net, como hemos visto, es una herramienta diseñada para producir encuentros sexuales ocasionales (aunque los usuarios también la utilizan para crear lazos de amistad/camaradería en áreas geográficas donde la homosexualidad los condena a la soledad y al ostracismo). Orientado hacia un público de hombres diversos (en cuanto a identidad sexual, edad, etnia, tipo de cuerpo, etc.), el sitio funciona, de acuerdo a Zago (2013) sobre una premisa omnipresente: la expulsión del afeminamiento.

En la portada y en los avisos que aparecen en el interior, se despliegan imágenes de hombres jóvenes (entre 20-30 años), cuyos cuerpos portan visibles marcas de virilidad, tales como musculatura desarrollada, vello facial, vello corporal, bulto o genitales expuestos, etc. Cada tanto suelen aparecer banners que promocionan páginas de contenidos pornográficos homosexuales o juguetes sexuales de la tienda manhunt. Traigo a colación la pornografía porque sólo a través de ella podremos interpretar cómo se configura el deseo erótico de los usuarios de manhunt.net.

Mowlabocus (2010) analiza el rol que ha cumplido la pornografía en la producción de la cultura digital homosexual. En este sentido, él afirma:

[q]ue hay una relación clara y específica entre el cuerpo digital y el cuerpo real en el ciberespacio ${ }^{18}$ homosexual masculino y que esta relación está estrechamente ligada a las estructuras de observación y consumo que son halladas en la pornografía homosexual. $(2010$, p. 81)

\footnotetext{
${ }^{18}$ Una crítica al concepto de ciberespacio puede leerse en Baym (2010).
} 
Deseos pixelados - sociabilidad homoerótica masculina en villa maría y la región (Córdoba, Argentina) a través de manhunt.net

Mowlabocus (2010), como así también Padilha (2014) y Miskolci (2015), aseveran que la pornografía es la única forma cultural disponible en la cual el deseo por otros hombres es presentado positivamente. Esto implica, lisa y llanamente, que los sitios destinados a varones con deseos homoeróticos están impregnados de modos de representación de los cuerpos directamente asociados con la industria pornográfica, motivo por el cual, el repertorio de modelos identificatorios a disposición de sus usuarios se restringe marcadamente (en contraposición al amplio repertorio de modelos identificatorios que la sociedad heterocentrada genera para varones y mujeres heterosexuales y que diariamente aparecen en los medios masivos de comunicación -tv, cine, revistas, internet-).

Los usuarios aprenden a crear sus perfiles recreando las imágenes porno, convirtiéndose así en modelos porno amateur. Asimismo, estos aprendizajes se van construyendo bajo la modalidad del "ensayo y el error", ya que los usuarios pueden modificar fácilmente sus perfiles conforme a las reacciones de la audiencia (según las visitas que hayan tenido, los guiños, mensajes o pedidos de chat recibidos, por ejemplo). Manhunt.net actúa, entonces, como una tecnología didáctica, un artefacto digital interactivo para una pedagogía de la gaycidad.

\section{REFERENCIAS BIBLIOGRÁFICAS}

BAYM, Nancy K. Personal Connections in the Digital Age. Cambridge: Polity Press. 2010.

FORCINITO, Karina (s/f). "Estructura y dinámica del mercado de telecomunicaciones en la Argentina. Aportes a la discusión pública sobre su regulación”, Página web de la Facultad de Ciencias Económicas de la Universidad de Buenos Aires. [Online], Disponible en: http://www.econ.uba.ar/planfenix/docnews/Transporte\%20y\%20telecomunicaciones/Forcinit o.pdf. Último acceso: 23-09-15.

GOFFMAN, Erving. Estigma. La identidad deteriorada. Buenos Aires: Amorrortu Editores. 1998.

IERAL, "Informe de Localización: Villa María". [Online]. Página web del Instituto de Estudios Económicos sobre la Realidad Argentina (IERAL) de la Fundación Mediterránea. s/f. Disponible en: http://www.ieralpyme.org/loc/pinv-filtromunicipio.asp?m=23. Último acceso: 23-09-15.

INDEC, “Accesos a Internet. Datos provisorios". [Online]. Página web del Instituto Nacional de Estadísticas $\mathbf{y}$ Censos. 10 de junio de 2005. Disponible en: http://www.indec.gov.ar/nuevaweb/cuadros/14/internet_06_05.pdf. Último acceso: 23-09-15.

INDEC, “Accesos a Internet. Primer trimestre 2014. [Online]. Página web del Instituto Nacional de Estadísticas y Censos. 17 de junio de 2014. Disponible en: 
http://www.indec.gov.ar/uploads/informesdeprensa/internet_06_14.pdf. Último acceso: 23$09-15$.

ILLOUZ, Eva. Intimidades congeladas. Buenos Aires: Katz Editores. 2007.

ILLOUZ, Eva. O amor nos tempos do capitalismo. Rio de Janeiro: Zahar. 2011.

LEAL GUERRERO, Sigifredo. La Pampa y el Chat. Aphrodisia, imagen e identidad entre hombres de Buenos Aires que se buscan y encuentran mediante internet. Buenos Aires: Antropofagia. 2011.

MELHADO, Rodrigo C. Vitrine do Desejo: um estudo sobre perfis de busca de parceiros do mesmo sexo no site Manhunt.net nas cidades de Araraquara e São Carlos. Relatório final. Universidade Federal de São Carlos. 2014.

MISKOLCI, Richard. Networks of Desire: The Specter of AIDS and the Use of Digital Media in the Quest for Secret Same-Sex Relations in São Paulo [Online]. Revista Vibrant. Virtual Brazilian Antrophology. Brasília, V. 10. n. 1. 2013. Disponible en: http://www.vibrant.org.br/issues/v10n1/richard-miskolci-networks-of-desire/. Último acceso: 20/06/2015.

MISKOLCI, Richard. San Francisco e a nova economia do desejo [Online]. Revista Lua Nova, São Paulo, 91: 269-295. 2014. Disponible en: http://www.scielo.br/pdf/ln/n91/n91a10.pdf. Último acceso: 20/06/2015.

MOWLABOCUS, Sharif. Gaydar Culture: Gay Men, Technology and Embodiment in the Digital Age. United Kingdom: MPG Books Group. 2010.

PADILHA, Felipe. O segredo é a alma do negócio: mídias digitais móveis e a gestão do desejo homoerótico masculino na região de São Carlos. Dissertação de Mestrado. Universidade Federal de São Carlos. Programa de Pós-graduação em Sociologia. 2015.

SIN AUTOR, "How are Alexa's traffic rankings determined?" Página web de Alexa. [Online]. Disponible en: https://support.alexa.com/hc/en-us/articles/200449744-How-areAlexa-s-traffic-rankings-determined-. Último acceso: 24-09-15.

SIN AUTOR, "Products. Manhunt". Página web de Online Buddies. [Online]. Disponible en: http://online-buddies.com/products/manhunt/. Último acceso: 24-09-15.

ZAGO, Luiz Felipe. Os meninos. Corpo, gênero e sexualidade em e através de um site de relacionamentos. Tese de Doutorado. Universidade Federal do Rio Grande do Sul. Faculdade de Educação. Programa de Pós-graduação em Educação. 2013. 